\title{
Cardiopulmonary resuscitation in the accident and emergency department
}

\author{
C. E. ROBERTSON AND K. LITTLE \\ Accident and Emergency Department, Royal Infirmary, Edinburgh
}

\section{INTRODUCTION}

Although cardiopulmonary resuscitation is commonly performed in the accident and emergency department, few studies have been reported as to the incidence, management and survival following cardiac arrest. We report our experience in a busy teaching hospital accident and emergency department.

\section{METHODS}

The Accident and Emergency Department at the Royal Infirmary of Edinburgh is the principal adult referral centre for a region which has a population of approximately 500000 . Sixty-five thousand new patients are seen in the department per annum. Children under the age of 13 years are normally seen at the Royal Hospital for Sick Children nearby, but on occasions children in extremis are referred to the department.

Criteria for inclusion in this retrospective study included any patient with cardiac arrest (absent major pulses together with loss of consciousness as documented by the senior doctor present) in whom attempts at cardiopulmonary resuscitation were made. Excluded from the study were patients brought to the department for formal certification of death and in whom no form of resuscitation was attempted. Patients in whom the cardiac arrest was related to trauma were also excluded.

All patients were managed in the resuscitation area, where facilities included standard resuscitation equipment, cardiac monitor, defibrillator and a mechanical automatic cardiac compression ventilation device (Michigan Instruments, Cardiopulmonary Resuscitation Model 1003), X-ray apparatus and equipment for the insertion of temporary transvenous pacemakers. All the patients were treated by one or more senior

Correspondence: Dr C. E. Robertson, Accident and Emergency Department, Royal Infirmary, Lauriston Place, Edinburgh EH3 $9 Y W$ 
staff members (registrars, senior registrar or consultant) and one senior house officer together with nursing staff from the department.

\section{RESULTS}

\section{Number of Patients}

Over a one-year period from 1 October 1981-30 September 1982, 98 patients received cardiopulmonary resuscitation in the department. This was $0.15 \%$ of the new patients attending the department.

\section{Age Distribution}

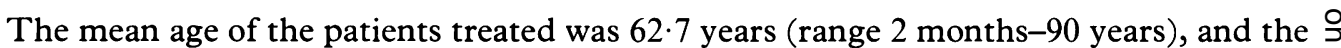
age distribution is illustrated in Fig. 1.

\section{Place of Arrest}

Inside accident and emergency -28

Outside accident and emergency -70

In the majority of the cases occurring outside the accident and emergency department cardiopulmonary resuscitation was commenced and continued by ambulance staff during transport.

The relationships between place of arrest and the presenting arrhythmia and survival are shown in Figs 2, 3 and 4.

Ventricular fibrillation was more common inside hospital. Asystole was more common outside. Survival was better if the arrest occurred inside hospital and the presenting arrhythmia was ventricular fibrillation. It is possible that patients who presented to the accident and emergency department in asystole had originally been in ventricular fibrillation.

Patients who gave a history of palpitations, chest pain or tightness, or dyspnoea were routinely connected to a cardiac monitor by the nursing staff prior to being seen by a

Table 1 Management of cardiac arrest in the accident and emergency department

Establish Airway (usually by Endotracheal Intubation) and commence ventilation

Commence External Cardiac Compression (manually or using Thumper)

Insert Central and Peripheral Venous Cannulae

Take samples for Arterial Blood Gas and Electrolyte analysis

Correct Acid-base and Electrolyte status where appropriate under biochemical guidance

Treat primary and secondary arrhythmias rationally 


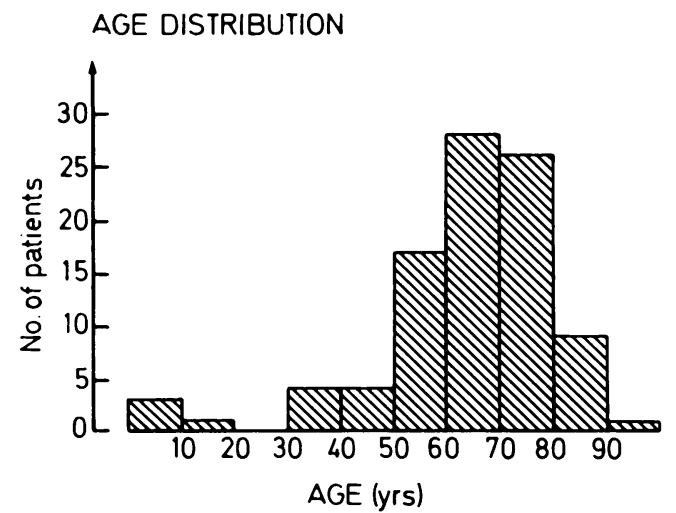

Fig. 1
INFLUENCE OF SITE OF ARREST ON PRIMARY ARRHYTHMIA

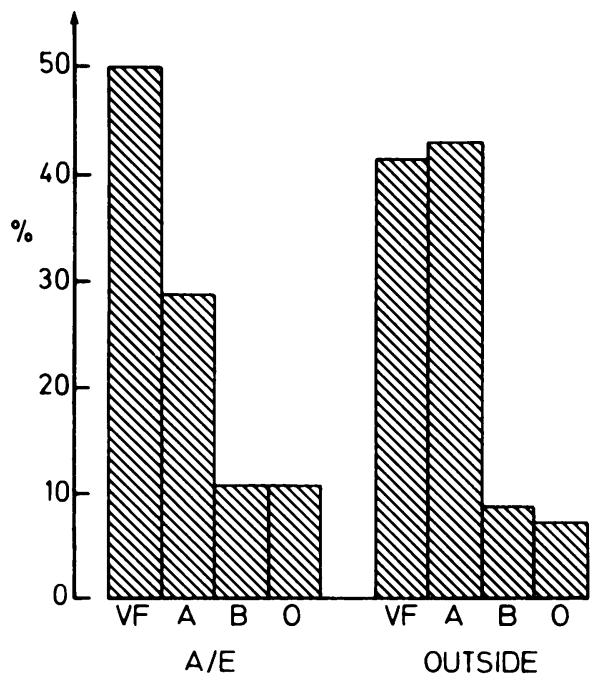

VF Ventricular fibrillation/tachycardia

A Asystole

B Complete heart block/ bradyarrhythmias

0 Other

Fig. 2

member of the medical team. Therefore, when cardiac arrest occurred in the department the patient was already attached to an electro-cardiographic monitor and trace.

A standard resuscitation protocol was followed (Table 1). All drugs were given intravenously and usually administered via an indwelling central venous catheter. A peripheral line was inserted first and then attempts made to cannulate the right subclavian vein by a supra-clavicular approach. Whenever DC conversion was required for the treatment of ventricular tachycardia or fibrillation, the initial energy applied was 200 Joules to an adult patient. If the arrhythmia was refractory further DC shocks of 400 Joules were given. If the patient was in asystole, intravenous injections of adrenaline, $1 \mathrm{ml}$ of 1:1000, followed by isoprenaline $100 \mu \mathrm{g}$ were given through the central line and flushed with saline. If unsuccessful then both would be repeated once and then atropine $0.6 \mathrm{mg}$ given. In addition, $10 \mathrm{ml}$ of $10 \%$ calcium gluconate was given intravenously for asystole or where electrical activity was present but contractility was poor. The decision to abandon resuscitation was influenced by the age of the patient, any available medical history, and the presence of poisons or hypothermia.

Following successful resuscitation, patients were transferred to the coronary care or one of the other intensive care units for further management. 
PRESENTING ARRHYTHMIA AND SURVIVAL

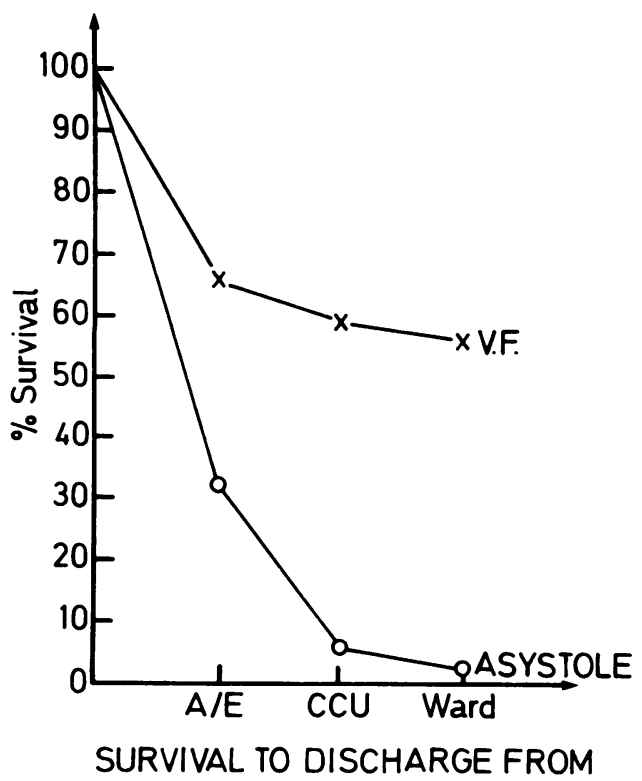

Fig. 3
THE INFLUENCE OF SITE OF ARREST ON SURVIVAL

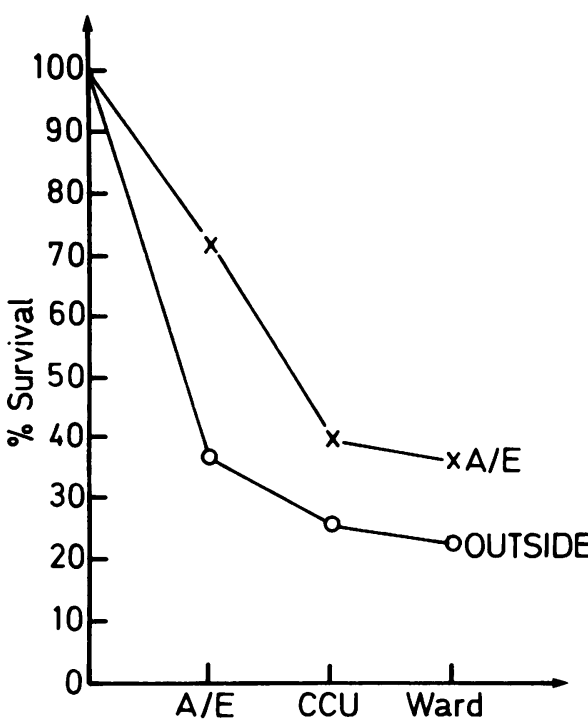

SURVIVAL TO DISCHARGE FROM

Fig. 4

The aetiologies of the cardiac arrest for those patients who survived to be transferre alive out of the accident and emergency department are listed in Table 3.

\section{Survival}

The short-term survival for patients sustaining a cardiac arrest (those patients who left the accident and emergency department alive) was $47 \%$.

The long-term survival (those patients who left the hospital alive) was $26.5 \%$.

For ventricular tachycardia or fibrillation, short-term survival was $65 \%$, long-term survival was $56 \%$. For asystole short-term survival was $31 \%$ and long-term survival was $1 \%$.

\section{DISCUSSION}

Few studies have been reported as to the results of cardiopulmonary resuscitation in the accident and emergency department. Piganol recently reported an overall survival rate of $4 \cdot 1 \%$ (Piganol, 1981), while in another study a $21 \%$ survival to hospital discharge was quoted (Peatfield et al., 1977). Survival following cardiac arrest in the accident and emergency department may be associated with a significantly greater chance of survival than in intensive care or general wards. 
Table 2 Primary arrhythmia documented in cardiac arrest

Ventricular Tachycardia/Ventricular Fibrillation

Asystole

Complete Heart Block/Bradyarrhythmias

Other

(Electromechanical Dissociations, Hyper/Hypokalaemia, atrial fibrillation with rapid ventricular response)

Table 3 Aetiology of cardiac arrest in patients surviving to leave accident and emergency department

Myocardial infarction/ischaemic heart disease

Hyperkalaemia (chronic dialysis patients)

Hypokalaemia ( $\mathrm{K}^{+} 1.8 \mathrm{mmol} / 1$ secondary to mucous secreting rectal tumour)

Near 'cot-death'

Subarachnoid haemorrhage

Our favourable results cannot be solely attributed to the patient population or disease process. The patients were generally elderly and suffering from ischaemic heart disease as in other studies. We would suggest that at least, in part, they are related to the fact that experienced medical staff were involved in and controlling the resuscitation process. Cardiac arrest teams frequently comprise junior staff working in unfamiliar and poorly equipped and staffed surroundings (Gray, 1981). Since it has been shown that few house officers can adequately perform cardiopulmonary resuscitation correctly using a training manikin (Lowenstein et al., 1981), this would appear to emphasize the importance of senior experienced staff involvement in cardiac arrest and the adequate training of junior staff.

Our results with patients in whom asystole was the presenting arrhythmia were very poor, but in keeping with previous studies (Lawrie et al., 1967; Wildsmith et al., 1972). While initial resuscitation was successful in nearly one third of cases, only one patient survived to leave hospital, presumably reflecting the major myocardial damage that asystole implies. Although temporary pacing may be of value (as indicated by the shortterm survival) we remain unimpressed by the long-term usefulness of the procedure with regard to asystolic cardiac arrest.

Long-term survival figures following successful resuscitation from cardiac arrest are encouraging (Eisenberg et al., 1982). We, therefore, believe that as far as the accident and emergency department is concerned, expressions of pessimism with regard to the role and usefulness of cardiopulmonary resuscitation are misplaced. Furthermore, it has been shown that if a bystander commences cardiopulmonary resuscitation then even further reductions in mortality can be achieved (Eisenberg et al., 1980). When techniques of cardiopulmonary resuscitation are further developed then substantial reductions in mortality will be achieved. 


\section{REFERENCES}

Eisenberg M. S., Bergner L. \& Hallstrom A. (1980) Out-of-hospital cardiac arrest: Improved survival with $\stackrel{8}{?}$ paramedic services. Lancet 1, 812-15.

Eisenberg M. S., Hallstrom A. \& Bergner L. (1982) Long-term survival after out-of-hospital cardiac arrest. New England fournal of Medicine 306, 1340-3.

Gray H. H. (1981) Letter. British fournal of Hospital Medicine 25, 4, 420.

Lawrie D. M., Greenwood T. W., Goddard M., Harvey A. C., Donald K. W., Julian D. G. \& Oliver M. F. $\frac{\text { क }}{\square}$

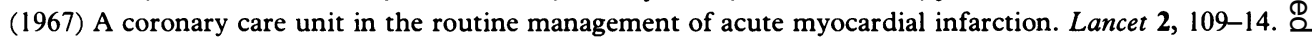

Lowenstein S. R., Libb L. S., Mountain R. D., Hansbrough J. F., Hill D. M. \& Slobbin C. H. (1981) ڤ Cardiopulmonary resuscitation by medical and surgical house officers. Lancet ii, 679-81.

Peatfield R. C., Sillett R. W., Taylor D. \& McNicol M. W. (1977) Survival after cardiac arrest in hospital. Lancet 1, 1223-5.

Piganol A. (1981) In Care of the Acutely Ill and Injured. A. K. Marsden \& D. H. Wilson (eds). Chichester, John Wiley and Sons Ltd.

Wildsmith J. A. W., Dennyson W. G. \& Myers K. W. (1972) Results of resuscitation following cardiac arrest: A review from a major teaching hospital. British fournal of Anaesthesia 44, 716-20.

Received 7 fune 1983; accepted for publication 22 August 1983 